\title{
Arte contra Verdade
}

\author{
Art against Truth \\ Art contra Verdad
}

\section{Rita Helena Sousa Ferreira Gomes}

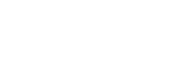

${ }^{1}$ Universidade Federal do Ceará, Sobral, Ceará, Brasil, ritahelenagomes@gmail.com

\section{Resumo}

Este artigo defende a arte como uma atividade/conhecimento pautado no reconhecimento de sua ficção, no acolhimento e valorização da experiência e da vida cotidiana e na abertura para a particularidade e intersubjetividade. Neste sentido, a arte é vista em sua contribuição potencial à epistemologia. Essa contribuição é desdobrada a partir do embate das qualidades da arte em relação à noção Moderna de Verdade, representada pela elaboração cartesiana. Conclui-se que a arte pode abrir caminhos para epistemologias mais aptas a lidar democraticamente com as diferenças.

Palavras-chave: Arte. Verdade. Diferença.

\begin{abstract}
The paper present art as an activity/knowledge characterized as a fiction that acknowledge itself as a fiction, embracing and having a positive recognition of experience and daily life, and by its opening to particularity and intersubjectivity. Thus, art is perceived in its potential contribution to epistemology. This potential contribution is unfolded through a confrontation between art's qualities and the Modern notion of Truth as elaborated by Descartes. On the paper's closure, we advocate that art provides a way to think epistemologies more suitable to deal democratically with difference.
\end{abstract}

Keywords: Art. Truth. Difference.

\section{Resumen}

El artículo defiende el arte como una actividad / conocimiento basado en el reconocimiento de su ficción, la aceptación y apreciación de la experiencia y la vida cotidiana, y la apertura a la particularidad y la 
intersubjetividad. En este sentido, el arte tiene una contribución potencial a la epistemología. Esta contribución se desarrolla a partir del choque de las cualidades del arte en relación con la noción moderna de verdad representada por la elaboración cartesiana. Se concluye que el arte puede abrir el camino a las epistemologías que están en mejores condiciones para abordar democráticamente las diferencias.

Palabras clave: Arte. Verdad. Diferencia.

No raiar da Modernidade, a pergunta sobre a possibilidade de conhecer o real e, logo, de atingir a verdade, concentrou boa parte dos esforços dos intelectuais da época. O problema da possibilidade e dos limites do conhecimento nos permite compreender muito do mundo contemporâneo, haja vista que do entorno dele emanaram teorias que moldaram nossas concepções de realidade, de sujeito, de ciência, de tecnologia, de trabalho, de política, de educação e, claro, de verdade.

De forma resumida, podemos dizer que, desde o final da Idade Média e durante todo o Renascimento, mudanças severas em diversas esferas abalaram a visão de mundo vigente na Europa, levando as pessoas a questionarem suas crenças, suas teorias e, em geral, sua forma de viver. Foi um período de profunda angústia e de intensa produção. Transformações que redesenharam definitivamente o planeta ocorreram: as grandes navegações, a reforma protestante, a contrarreforma, o resgate dos valores humanistas, a derrocada do feudalismo e a ascensão das bases do capitalismo são apenas alguns dos muitos exemplos que poderiam ser listados.

Tais transformações se associam direta ou indiretamente também com o problema do conhecimento. As grandes navegações indicaram uma compreensão geográfica do mundo que desafiava aquela que durante séculos vigorou, ao mesmo tempo em que confirmaram que a Terra era bem diferente do que se acreditava até então. A reforma protestante de Lutero, supondo que um indivíduo inspirado poderia estar mais 'correto' que um concílio, fez tremer as concepções religiosas que, desde Santo Agostinho, se sustentavam pela conciliação entre fé e razão. O humanismo renascentista trouxe à tona a dignidade do humano por si mesmo (independentemente de ser uma criatura à imagem e semelhança de Deus), acarretando uma mudança nos cur- 
rículos escolares $^{1}$ e na revalorização da vida ativa ${ }^{2}$. O enfraquecimento do feudalismo surge a par e passo dos questionamentos da Revolução Científica sobre a imobilidade e centralidade do mundo no universo, tendo em vista que há uma relação íntima entre a ordem astronômica e a hierarquia que garantia a imobilidade e centralidade do rei e da Igreja em termos sociais.

O problema epistemológico que azucrina os juízos dos filósofos nos séculos XVI e XVII não é, portanto, um problema meramente abstrato. Complexamente, ele é tanto o resultado de um mundo que se revolve, posto que as transformações concretas exigem da filosofia uma posição; quanto uma de suas causas, já que essas mudanças concretas dialogam e são influenciadas pelas manifestações filosóficas que são produzidas. Isso significa dizer que, jogar luzes nas questões epistemológicas do início da Modernidade, não é um exercício inócuo para nossos dias, mas pode nos auxiliar não só a compreender, mas também a agirmos de modo bem diferente do que estamos fazendo.

Sublinhar como a questão da verdade está imiscuída e constrói o que nos rodeia e pressiona é caminhar na senda aberta por Foucault (2000, p. 132)3 que revela que "Truth' is to be understood as a system of ordered procedures for the production, regulation, distribution, circulation, and operation of statements '”. Ora, se a verdade é um sistema de ordenação dos discursos, então é tarefa urgente de qualquer sociedade saber a que sistema estão submetidos seus discursos e práticas. Voltar a Descartes é empreender parte dessa jornada de compreensão e, logo, de reconhecimento das implicações e limitações do sistema. Visto assim, minha proposta neste escrito é fornecer alguns elementos para que possamos olhar o sistema de verdade-poder com o intuito de perceber como ele molda o mundo. Não obstante a força do atual sistema de verdade-poder ter, segundo minha análise, efeitos extremamente negativos na sociedade, em especial no tocante às artes e à interseção entre educação e arte, há nele brechas possíveis de serem exploradas. A tese central deste artigo é que a arte - tal como a apresentarei - nos coloca diante de outras perspectivas, quiçá mais interessantes e democráticas, de lidar com o conhecimento.

Eis que, com o objetivo de lançar uma provocação ao conceito cartesiano de verdade (e aquilo que ele engendra) a partir da arte, estruturarei o texto de modo a discutir: a) como Descartes caracteriza a verdade e o conhecimento verdadeiro, b) como a concepção de verdade cartesiana se vincula com uma visão determinada de realidade marcada pela matematização e controle; c) como a arte - tal como a circuns- 
creverei - é uma atividade privilegiada para contestar a verdade cartesiana, ampliar horizontes ainda pouco explorados e contribuir para uma abertura mais democrática relativamente à diferença.

\section{A verdade de Descartes}

Como visto acima, a Modernidade foi marcada por uma constante busca de resolver o problema do conhecimento. Os modernos, em geral, haviam perdido a confiança plena em sua capacidade de apreender a estrutura do universo através da razão. Essa desconfiança, claro, não era à toa: de todos os lados (ou de quase todos) havia algo ou alguém que punha em xeque um conhecimento "verdadeiro" assentado por séculos. Para completar a angústia que acompanha a perda dos nortes, várias vozes dissonantes emergiam propondo soluções. Uns insistiam, muitas vezes pela força como fez a inquisição, em manter as perspectivas tradicionais. Outros defendiam a impossibilidade de alcançarmos um conhecimento seguro. Uma terceira via buscava reavaliar o intelecto humano no intento de delinear o que lhe era possível ou não conhecer. Das filosofias redigidas pelos representantes dessa terceira via brotam as bases que servem de fundamento para organização da ciência moderna e, como não poderia deixar de ser, para consequente estruturação de muito do que compõe a sociedade contemporânea.

Um dos maiores, senão o maior, personagem disso que nomeei terceira via é Descartes. Genial e profundamente atento ao seu tempo, ele se dedica a comprovar a possibilidade de conhecer do intelecto humano, além de objetivar criar uma base metafísica firme para o conhecimento. Nesse sentido, duas obras se destacam: $O$ discurso do Método e as Meditações Metafísicas 4 . O primeiro voltado ao "grande" público, omitindo argumentos potencialmente mais polêmicos, e o segundo destinado aos mestres de filosofia da época, na esperança de convencê-los da importância e validade da teoria ali condensada.

Seja n'O Discurso, seja nas Meditações, a ideia cartesiana de verdade precisa ser entendida juntamente com o processo que nela culmina, a saber, um processo metódico que consiste em duvidar exageradamente das concepções que se tem, de modo a, ao final desse empreendimento, restarem apenas ideias consideradas plenamente seguras. Pelas mãos de Descartes, somos conduzidos(as) a abandonar, mesmo que temporariamente, tudo que possa ser falso e, feita essa limpeza obsessiva, chegar às ideias claras e distintas. 
A clareza e a distinção são, assim, as características, os critérios da verdade. A clareza combate a confusão dos sentidos, da materialidade, do cotidiano. A distinção está, de certa forma, implicada na própria exigência de clareza, uma vez que separar (distinguir) é acabar com a fusão das coisas, colocando-as em espaços conceituais (e, se pensarmos na ciência contemporânea, até mesmo físicos) específicos.

Clareza e distinção são, então, não só resultantes do processo de conhecer, mas também diretrizes que o guiam. A mentalidade cartesiana, marcada pela matemática, desde o início torna conceitualmente isolado aquilo que é concretamente emaranhado complexamente. Na sua busca por ideias claras, Descartes horizontaliza todos os sentidos, paradoxalmente misturando-os e confundindo-os todos em uma só coisa. Procede do mesmo modo com os sonhos, com os 'tipos' de ideias, com as coisas extensas e com os sujeitos.

Se Descartes pontua e generaliza o mundo e os sujeitos através do recurso à clareza e distinção, é importante lembrar que ele o faz para garantir um pressuposto de tradição milenar e de ampla aceitação na história da filosofia. A noção de verdade, por excelência, se associa, desde a Grécia Antiga, com a captação em conceito do imutável e do universal. Verdadeira é a ideia que captura conceitualmente aquilo que não está submetido aos caprichos do tempo e do espaço. Ou, ainda, no rastro de Aristóteles: a verdade é a adequação do conceito ao real ${ }^{5}$. Isso significa que a categoria de verdade nos remete, tradicionalmente, a uma fronteira entre o discurso e a realidade. Na percepção Aristotélica, por exemplo, não se questiona a capacidade da razão de cruzar essa fronteira e discursar em plena correspondência com o real. Dito de outra forma, ainda que possamos nos enganar quando usamos a racionalidade, atribuindo algo que não é àquilo que é, ou algo que é àquilo que não é, não há nenhum impedimento da razão em si de apreender via logos a realidade. Com os abalos sofridos na esfera do saber no período da Renascença e da Modernidade, todavia, os filósofos passam a se perguntar se o engano da razão é exceção ou regra. Descartes, ao resgatar os pilares clássicos, procura salvaguardá-los, ainda que os reconfigurando para se adaptarem, resistirem e darem respostas aos novos tempos.

Evidencia-se que os modernos não rompem por completo os laços com os antigos e medievos, embora os interroguem e os rechacem em vários aspectos. Aqui, o que vale ressaltar, é que, como na tradição clássica da filosofia, Descartes vincula verdade, universalidade e realidade. Simultaneamente, porém, Descartes trava um embate seríssimo com essa tradição, deslocando a ordenação lógica do mundo de uma exterioridade 
para o sujeito. Ou seja, em Descartes não somos sujeitos a contemplar passivamente uma ordem racional do universo pré-pronta, somos já criadores ativos. Se não criamos o mundo propriamente dito, ao menos nossas ideias, segundo o pai da filosofia moderna, são representações objetivas das coisas no intelecto. "Em Descartes, pela primeira vez, a verdade passa a ser uma construção originária do sujeito. Como consequência, a verdade sem sujeito é superada pelo sujeito da verdade" (BITENCOURT, 2017, p. 9).

Afirmar que a verdade é uma construção originária do sujeito, entretanto, não é o mesmo de dizer que a verdade independe do real ou é "subjetiva". Descartes investe em importantes argumentos filosóficos para defender que a autonomia do sujeito na esfera do conhecimento é garantida por um Deus não enganador, que faz corresponder a certeza intelectual advinda de uma evidência (ideia clara e distinta) àquilo a que ela se refere na realidade. Em outras palavras, Descartes recorre, uma última e única vez, ao ser supremo e bondoso para que ele assegure que a razão bem conduzida pelo método é capaz de acessar a realidade tal como ela é. “(...) porque toda concepção clara e distinta é sem dúvida alguma coisa real e positiva e, portanto, não pode tirar sua origem do nada, mas deve necessariamente ter Deus como seu autor...” (DESCARTES, 2005, p. 95/96). Daí porque apenas com a descoberta da existência de Deus - uma ideia clara e distinta que emerge na terceira meditação - é que o sujeito cartesiano pode, enfim, sair de 'dentro de si' e alcançar o mundo exterior.

Desta feita, na filosofia cartesiana vemos tanto a emergência da subjetividade, quanto seu casamento com a objetividade e com a universalidade. O filósofo francês consegue a proeza de validar via subjetividade a verdade, garantindo a autonomia do sujeito frente à divindade (ou ao Cosmos ordenado) na mesma tacada em que afasta os "riscos" da particularidade. Em português simples, Descartes consegue fundar a verdade no sujeito, sem cair num subjetivismo relativista.

Por um lado, Descartes dá autonomia ao conhecimento humano - fazendo-o independente da confirmação constante de Deus através da Igreja e das Sagradas Escrituras - ao demonstrar que um uso metódico da razão é capaz de levar qualquer sujeito racional a afirmações seguras e partilháveis com outros seres racionais ${ }^{6}$. Por outro, a demonstração cartesiana pressupõe uma universalidade da subjetividade. O pensador consegue fazer essa amarração esvaziando o sujeito de particularidades. Ou seja, apesar de Descartes iniciar suas obras ${ }^{7}$ num tom bem pessoal, falando de sua meditação, de sua trajetória individual, quando o procedimento metodológico é posto em ação a partir da dúvida hiperbólica, todas essas particularidades são apagadas como 'potencialmente 
falsas'. Isso implica que a fundação da subjetividade no campo da filosofia ocorre sob um sinal dúbio: fala-se de subjetividade de uma forma objetiva. A objetividade é conquistada em nome de uma verdade. É porque se busca clareza e distinção que o sujeito tem que ser reduzido a uma coisa pensante (res cogitans) que se separa do mundo, do cotidiano, das experiências e dos demais sujeitos. Só depois de 'purgado' de suas especificidades o sujeito cartesiano está pronto para conhecer propriamente. O retorno do sujeito 'purgado de subjetividade' ao mundo, assim, é plenamente vigiado. $\mathrm{O}$ acesso ao mundo ocorre, mas precisa dispensar as suas qualidades e, em seu lugar, identificar o real ao quantificável.

Embora não seja correto asseverar que não há nenhum espaço para as experiência na filosofia cartesiana, o que fica, após uma análise mais rigorosa de sua teoria do conhecimento e de sua metafísica, é que pelos sentidos não se alcança clareza e distinção, por isso aquilo que advém deles deve ser reduzido às suas características matematizáveis para que possa entrar na escala da ciência e receber nela lugar.

Conhecimento em sentido estrito só é possível quando se retorna àquilo que é percebido de forma clara e distinta. Somente então podem formar-se idéias que representem o fundamento para um conhecimento seguro. E somente sobre tal fundamento se pode 'construir algo firme e duradouro nas ciências' (PERLER, 2007, p. 116).

Estritamente, a experiência não se adequa às exigências epistêmicas de Descartes porque ela resiste aos conceitos gerais. Duarte Jr. (1995) nos esclarece o motivo dessa resistência ao discorrer sobre os sentimentos e sua relação com o conhecimento. Chamando atenção para a peculiaridade dos sentimentos, Duarte Jr. nos lembra que a linguagem conceitual consegue apontá-los, mas não descrevê-los, tendo em vista que ao dizer, por exemplo, que ‘tenho frio' ou que ‘tenho saudade', não consigo capturar pelo conceito de frio e saudade o 'meu frio' e a 'minha saudade'. A contingência dos sentimentos é tal que, sequer posso afirmar que todas as vezes que usei o conceito 'frio' na frase ‘estou com frio’ me referi à mesma sensação interna.

A necessidade de redução das qualidades às quantidades, em nome da clareza e da distinção, afeta, como vimos, não só o âmbito do saber, mas o próprio sujeito. O sujeito cartesiano - e, em geral, o sujeito moderno - é marcado pela "perda" do 
corpo, dos enraizamentos sociais, da historicidade e, também, pela obrigação de podar-se para mostrar-se como realmente é: sua vontade infinita deve ser submetida às rédeas da razão ${ }^{8}$.

Na prática, a metafísica cartesiana atua fortemente para a construção do mundo moderno e contemporâneo em muitos aspectos. Aqui, me interessa sobremaneira destacar dois deles: 1) a relevância da matematização para a validação dos conhecimentos, e 2) a justificação racional do exercício do controle de si e do mundo. Ambas derivações (e, em certa medida, pressuposições) da filosofia cartesianas são diretamente alinhadas à sua noção de verdade.

\section{Matematização e Controle a partir da filosofia cartesiana}

Na sexta e última meditação, Descartes se empenha em demonstrar que podemos conhecer não apenas as realidades da alma, mas também aquelas extensas (materiais). Buscando trazer de volta aquilo que relegou à falsidade com sua dúvida hiperbólica, ele retorna às coisas que percebemos pela via dos sentidos:

Todavia, talvez elas não sejam inteiramente tais como as percebemos pelos sentidos, pois essa percepção dos sentidos é muito obscura e confusa em várias coisas; mas, pelo menos, há que se admitir que todas as coisas que nele concebo clara e distintamente, ou seja, todas as coisas, falando de modo geral, que estão compreendidas no objeto da geometria especulativa, nele encontram-se verdadeiramente. (DESCARTES, 2005, p. 120/121).

A passagem acima manifesta o estatuto que a ciência moderna terminou por adotar em relação aos corpos, ao cotidiano e aos sentidos ${ }^{9}$ : o que há de verdadeiro neles é aquilo que pode ser submetido à lógica matemática (geométrica). Indo além, ao ler a citação, podemos vislumbrar o motivo das chamadas 'ciências exatas' servirem de referência até hoje para as demais. Somente no campo da quantificação, a confusão e as desavenças que atravessam as diferentes suposições teóricas sobre um fenômeno podem ser dirimidas. Só sob essa égide, a ciência pode desenvolver-se recorrendo às leis naturais.

Para melhor compreender a relação entre as leis naturais e a matematização, tomemos o exemplo da lei da gravidade. Antes da ciência moderna, os filósofos da natu- 
reza explicavam os fenômenos físicos de acordo com as qualidades específicas de cada objeto: uma pluma, tendo natureza diferente de uma pedra, tendia a permanecer mais tempo no ar, enquanto a natureza da pedra a fazia ficar no chão. Com a matematização da natureza ${ }^{10}$, os corpos passam a ser analisados naquilo que tem em comum, ou seja, naquilo em que não lhes é específico, como é o caso da figura, da massa e do volume. Por observarem os aspectos comuns dos corpos, os pensadores podem fazer considerações gerais sobre eles, encontrando explicações universalmente válidas e aplicáveis a qualquer ente natural, as chamadas leis de natureza. Assim, a explicação sobre a queda dos corpos pode se universalizar, posteriormente, pela introdução da lei da gravidade, que prescinde totalmente de uma análise específica da natureza particular do corpo que cai.

Não é sem motivo, pois, que a matemática e a geometria rapidamente alcançaram o status de ciências exemplares. Ao longo dos séculos, não foram poucos os esforços para aproximar as mais diversas áreas de saber de seu modelo. Se você, leitor(a), fizer uma rápida procura, achará inúmeras dessas tentativas ligadas à ética, à linguagem, à política, às ciências humanas e sociais. Mesmo em esferas aparentemente mais afastadas das ciências, a presença modelar da matemática se faz sentir. Barbosa (2012, p. 79), discorrendo sobre a arte-educação no Brasil, retoma: "O texto da lei de 1901 acerca do ensino do Desenho dizia ainda: '(...) As formas naturais que se tiverem de desenhar, hão de ser primeiramente reduzidas às geométricas em que se basearam"”.

O espraiamento da geometria e da matemática como referências reforçam ainda novas percepções sobre aspectos essenciais da vida cotidiana ${ }^{11}$. Ingold (2007), sob os pilares erigidos nas formulações de Certeau, mostra a diferença fundamental na lida com o espaço através da análise dos mapas de antes e depois da Modernidade. Com a Idade Moderna, os mapas deixam de 'narrar' uma movimentação dos habitantes sobre um espaço e passam a assumir uma posição que faz crer que eles correspondem diretamente à estrutura do mundo. Assim como na metafísica cartesiana, as qualidades abandonam a cena para que as características gerais e submissas ao número possam assumir: "But the world that is represented in the map is one without inhabitants: no one is there; nothing moves or makes any sound" (INGOLD, 2007, p. 24) ${ }^{12}$.

Dentro desse mesmo olhar, identificamos uma alteração significante quanto ao tempo. Duarte Jr. (2000, p. 43) realça como desde o século XI no interior dos mosteiros a preocupação com um maior regramento dos louvores e labuta diários afetaram a medição do tempo. Com a Modernidade, a importância da medição do tempo ganha 
ainda mais destaque. O relógio mecânico, símbolo desse momento da história, mostra uma nova percepção do tempo. Nessa perspectiva, o tempo opera em linha reta, fatiada e independente dos ciclos naturais. Quantificar precisamente o tempo, bem como mapear exatamente o espaço, é abstrair-se das particularidades inerentes à natureza, afastando-se daquilo que nos cerca como referencial da vida. Desta feita, matematizar o mundo é fugir do campo confuso onde a vida cotidiana acontece, criando para ela uma instância regulatória de ordem puramente conceitual.

Destarte, a quantificação e matematização do mundo propostas/reforçadas pela metafísica cartesiana articulam-se com um paradigma mecanicista de universo ${ }^{13}$. Esse paradigma se caracteriza por compreender o universo como uma grande máquina e, como tal, ausente de qualquer alma ou espírito, indiferente e passível de ser destrinchado a serviço dos projetos humanos.

Mundo sem Deus e sem alma, a natureza como que se dessacraliza, e se abre ao cálculo e à análise matemática. Pensada como combinação de matéria e movimento, não é mais necessário imaginá-la dotada de uma espontaneidade vital: bastam a matéria e as forças exercendo-se sobre ela. Uma natureza mecânica auto-regulável e matematizável, tal é a physis dos modernos: um agregado de átomos justapostos, dirão uns; uma extensão ou corpo geométrico, dirão outros (DOMINGUES, 1991, p. 74).

A matematização associando-se à lógica mecanicista, assim, abre o caminho para que o conhecimento científico 'fuja' e, simultânea e paradoxalmente, desça à terra com a intenção de controlá-la e manipulá-la de acordo com as ambições humanas. A máxima baconiana de que "saber é poder" ganha pleno sentido, desembocando, em última instância, nas criações tecnológicas que marcam a sociedade hodierna.

Há, pois, uma relação importante entre a verdade cartesiana, a criação moderna e o controle. Pela necessidade de atingir uma verdade segura, Descartes sustenta ser o corpo uma máquina. O corpo, assim como a natureza, se torna pura materialidade, sendo passível de intervenções. "The Cartesian machine results from the dismemberment of the natural body and its resynthesis, manipulation, and control according to the dictates of a rational model" (JUDOVITZ, 2004, p. 72) ${ }^{14}$.

A analogia entre natureza e técnica atesta, como grifa Judovitz (2004), um apagamento da distinção entre natureza e artifício. Contudo, essa quase indistinção entre o 
natural e o artificial só pode operar pelo signo do controle e de uma criação interessada. A natureza é esvaziada pela razão, que afirma sua força como soberania, como rompimento com o mundo. A razão parece ter como pré-requisito de suas construções a destruição. É preciso destruir qualquer traço de 'anima', destituir de significações o objeto para, então, sobre esse 'vazio' erguer o novo. O controle resulta da vacuidade contextual da razão, de uma metafísica que defende que a razão é algo desvinculado do particular. Isso implica em assumirmos que a autonomia do sujeito do saber moderno teve como preço a submissão de todos os Outros. Em nome da construir uma ciência, instauramos um intenso dualismo entre sujeito/objeto, entre mente/corpo, entre humanos/não-humanos, entre eu/outro. Esse dualismo não se sustenta se estiver aquém do poder, do controle, da possibilidade de manipulação. Todo poder supõe um par de opostos: um dominado e um dominante.

Como era de se esperar, não tardou que a ânsia e o alastramento do desejo de controle moderno nos alcançassem. Como aponta Morin (2005, cap. 4), inicialmente acreditávamos que o domínio da natureza dizia respeito ao desabrochar pleno da humanidade. Há alguns anos, porém, nos demos conta que o desenvolvimento técnico não serviu só à emancipação humana, mas também criou novas formas de manipular o próprio humano. Vandenborn (2014, p. 1), por seu turno, parece retificar esse salto da manipulação do campo exclusivamente epistemológico para o psicológico:

The current dominant conception of selfhood in North America - the so-called 'individualistic self - is characterized as a masterful, bounded and autonomous self with "specific psychological boundaries, an internal locus of control, and a wish to manipulate the external world for its own personal ends" (Cushman, 1990, p. 600 $)^{15}$.

Marcel Hénaff (1995, p. 216), em seu artigo sobre Sade, nos convoca a enxergar como o controle e o poder de manipulação moderna afetam nossos corpos e nosso prazer. "The description of the bodily organs devoted to pleasure never goes without an evaluation of numerical quantities; this is because the very statement of those measurements is supposed to found the value of the designated object"16.

Pela citação, notamos, mais uma vez, a quantificação como signo da medida que é fundante para o conhecimento moderno. O valor de um objeto está, nesta lógica, naquilo que dele podemos quantificar e controlar. O corpo máquina, emanado neces- 
sariamente da cisão com a mente, passa a exigir um outro que o controle, ainda que o corpo pertença a outro humano. Como esse controle é assumido, segundo a metafísica cartesiana, pela mente, a representação torna-se mais importante que a realidade. $O$ prazer, encarcerado no reino isolado da mente, passa a ser situado na organização, na contabilidade, na ordem daquilo que pode ser dissecado e medido por todos. Isso torna curta a distância entre o prazer contabilizável e a violência. O prazer emanado da quantificação advém do controle sobre o corpo e não do corpo propriamente dito. O corpo passa a ser objeto de domínio, um objeto do qual se extrai o prazer e não o locus do prazer. Em Sade, essa “extração” do prazer do corpo máquina é extrema: tudo é válido, até mesmo submetê-lo à brutalidade extraordinária para que ele atenda aos desígnios da representação.

Hénaff (1995, p. 214) nos incita, ainda, a vincular o extremismo libertino de Sade com aos primórdios da industrialização. Seguindo nessa seara, somos levados(as) a entender sob um novo ângulo a necessidade de consumo que assola os indivíduos na sociedade capitalista contemporânea: é preciso arranjar um apoio material visível e quantificável para obtermos nosso prazer, e, mais ainda, o nosso ser. O sujeito se reduz ao que se apresenta concretamente ao domínio da abstração imposta pela mente. Sou o que tenho, porque a abstração moderna só trabalha a partir da redução à quantidade. O prazer, a felicidade, o sujeito e tudo o mais o que é inefável (irredutível aos números) tornam-se inalcançáveis, justamente porque se ligam àquilo que é, por natureza, incompatível com a quantificação e com a medição.

Novamente, Vanderborn (2014, p. 47), caminhando lado a lado com Cushman, nos respalda:

... Cushman submits that is the essence of the current Western conception of selfhood, that of the 'empty self'. This 'empty self', severed and evacuated from the communal traditions that once provided orientation to what constitute a meaningful and fulfilling life, now look to obtain meaning and fulfillment through acts of consumption ${ }^{17}$.

Ao final dessas conjecturas, talvez não seja exagerado supor que, o afã moderno pela verdade, separou o viver do conhecer, relegando o primeiro a um posto menos importante. 


\section{E a arte com isso?}

Olho para o texto e vejo o quanto me delonguei naquilo que parece ser 'demasiadamente filosófico'. Imagino-me uma leitora e, de pronto, me vem a pergunta em tom impaciente: o que tudo isso tem a ver com a arte? A resposta a essa questão embaralha tanto o porquê essas considerações são relevantes para entendermos o espaço da arte hoje $\mathrm{e}^{18}$, quanto a contribuição que vislumbro na arte para ensejarmos uma transformação social mais ampla e profunda.

Sem dúvida, tudo que coloquei acima afeta a sensibilidade, a beleza e a arte. Não julgo que a arte paire no ar e se furte dos efeitos da Modernidade e sua verdade. Se reconheço que vivemos num mundo no qual o prazer e o desprazer são quantificados, em que a beleza é mercadoria, em que os sentidos só são despertados pelo choque exagerado das cores, dos sons, das atuações, não deixo de apostar minhas esperanças na dimensão estética.

Tomo que a arte pode ir - e, de determinada forma, já vai - contra a verdade dos modernos, pois nela entrevejo um espaço ${ }^{19}$ privilegiado para a experiência. $\mathrm{Na}$ arte, a experiência, os sentidos e o cotidiano não são renegados por serem obscuros e confusos. São, isso sim, trazidos como componentes essenciais para a obra. Pois aquilo que é para uma concepção de verdade um problema, adentra na arte como riqueza de possibilidades, multiplicidade e abertura de significações. Essa valorização da experiência, que é sempre situada e arraigada, recoloca a vida como um fim e não como um meio; e "Life as an end is qualitatively different from life as a mean" (MARCUSE, 1968, p. 17) ${ }^{20}$.

A instrumentalização da razão, como vimos nas páginas anteriores, se vincula intimamente à instrumentalização da vida. Tomar a vida como fim é tomar os sujeitos como criadores. Mas a criação, aqui, não é aquela interessada e controladora dos modernos, antes é uma atividade que mais se assemelha a dizermos para onde queremos ir. Viver não é, neste sentido, simplesmente não ter morrido, viver é ser capaz de criar a própria vida conscientemente. Falo de criação consciente aludindo a uma autonomia que reconhece complexamente a imersão daquilo que se cria no mundo (ou seja: a criação não é fruto de um sujeito puro e sem contato com o Outro), mas que não assente que haja uma determinação em sentido estrito daquilo que foi criado pelo mundo (ou seja: o encontro com o Outro ou a imersão no mundo não apaga a particularidade e a subjetividade do criador). 
Se pela noção de verdade cartesiana, a experiência, as particularidades e a vida cotidiana são negadas em sua diferença, sendo alocadas no campo da 'não-verdade', na arte elas são positivamente convocadas. Para existir, a arte exige e me coloca diante do Outro. Outro com 'o' maiúsculo, porque não é só outro humano, mas tudo o que se apresenta como diferente. O artista pede o público. A obra se completa pelo sentido atribuído por quem com ela interage.

Uma obra de arte pode indicar uma determinada direção aos meus sentimentos (...). Porém, a maneira de viver este sentimento (o seu como) é dada por mim. (...) Neste sentido é que é o espectador completa a obra: vivendo-a segundo as suas peculiaridades (DUARTE JR., 1995, p. 94. Itálicos no original).

Diferente da ciência cartesiana, que pensa e coloca o Outro apenas no final do caminho (o beneficiário e possível continuador da obra ou o objeto a ser desvelado), a arte é feita para estabelecer uma relação com ele. Assim como a piada que só se torna válida e reconhecida como tal com a risada emitida pelo outro, também a arte requer em sua incompletude manifesta a presença de algo que lhe ultrapassa. Consequentemente, com a arte, o império do sujeito isolado e resguardado do mundo é substituído pelo encontro. Abrimo-nos, assim, para a intersubjetividade.

Pela via da arte, portanto, é viável o reconhecimento de multidimensionalidade da vida, que congrega e excede o dualismo entre conceitual e experiencial, sujeito e objeto, corpo e mente, eu e outro (para nomear só alguns dualismos). Por uma estrutura que lhe é própria, a arte tende a abraçar a complexidade multidimensional. Contrariando a clareza e a distinção da verdade, na arte os ditos 'opostos' estão imbricados sem possibilidade de serem extirpados um do outro ${ }^{21}$. Mais ainda, esse imbricamento não é visto de antemão como negativo e, por conseguinte, não exige que um lado se sobreponha a outro. Reconhecer que existem dimensionalidades complexamente enredadas evita que se assuma, a priori e por uma necessidade conceitual (que, obviamente, apresenta-se nas práticas), a hierarquia e os antagonismos rígidos que, por simplificação impeçam o florescimento das possibilidades.

Ao convidar/convocar o Outro, a arte pode abrir uma fresta para lembrarmos que somos como uma colcha de retalhos dos encontros e desencontros que tivemos ao longo da vida, que somos singulares e irrepetíveis porque somos plurais. Complexamente, assim como a banda de Möbius ${ }^{22}$, não há, na arte, uma barreira fixa entre 
interior e exterior - a arte acontece no emaranhado entre artista, obra, público, mundo. Nessa fronteira flexível, a arte mostra-se capaz de reunir o contraditório e requer do artista e do público uma mobilização como seres complexos que são indistintamente corpo/mente/mundo, eu/Outro.

Porque não se limita ao campo conceitual, a arte tem potência para abarcar a multiplicidade de significações. Quer dizer, em tese, não cabe na arte a expectativa de uma perspectiva 'correta'. Se pelo conceito de verdade há uma correspondência entre discurso e mundo, sendo a realidade capturada, na obra de arte não há um sentido único e fixado. Sob esse ponto de vista, a obra de arte não pode ser, nunca, plenamente agarrada. A exigência do outro implicada na arte a torna, necessariamente, inacabada, incompleta e inesgotável. Nem o criador-artista pode dizer-se possuidor do sentido da obra.

Desta sorte, avisto uma aliança da arte com a proposta de Haraway (1995, p. 190) de uma nova objetividade: "Objectivity is not about disengagement but about mutual and usually unequal structuring, about taking risks in a world where 'we' are permanently mortal, that is, not in 'final' control. We have, finally, no clear and distinct ideas" ${ }^{23}$.

A arte, na sua posição privilegiada de não ser ciência, pode desmascarar a própria ciência, a política e todas essas esferas que se pretendem objetivas e transparentes. Descompromissada com a verdade que deseja capturar em seu discurso o real, a arte pode atuar como reveladora da 'ilusão do real'. Para entender o que quero dizer com 'ilusão do real' retornarei ao próprio Descartes para fins de exemplo.

Como apontei brevemente, todos os argumentos cartesianos partem do pressuposto de que ele não assume como certo algo que não seja claro e distinto, portanto, todos os preconceitos são, supostamente, excluídos por sua dúvida metódica. Todavia, ao longo do desenrolar das páginas d'O Discurso e das Meditações o que vemos é que todas as ideias 'não claras' continuam presentes e tomam parte no processo argumentativo, mesmo que precedidas pela negação ou ocultadas em sua significação. Por exemplo, quando ele afirma que sou "uma coisa que pensa" (Cf. DESCARTES, 2005, p. 47 \& DESCARTES, 1973, p. 54/55) não há qualquer clareza ou evidência sobre o que é 'coisa' ou 'pensa'. Eis que, toda a 'clareza e distinção' que podem ser 'descobertas' não são independentes das coisas 'não claras e não evidentes' que lhe dão sustentação. Por isso, ainda entram em jogo suas sensações, suas memórias, suas crenças, embora elas não 
sejam reconhecidas como participando da cena. Indo mais longe, se formos radicais na proposta cartesiana de só nos pautarmos pelo que é claro e evidente, teríamos, inclusive, de abdicar da linguagem que, em nenhum caso, é clara e evidente. Assim, a proposta cartesiana de capturar o real em si objetivamente (aqui no sentido usual e não no de Haraway) falha desde sua mais primária semente.

A minha provocação é defender que todo e qualquer conhecimento (para ficar restrita ao âmbito da epistemologia) é uma ficção. Ficcionamos o real em cada teoria e em cada ação que temos. Teorias e práticas não são neutras e, logo, revelam e chancelam um certo olhar, necessariamente limitado e parcial como qualquer olhar, sobre o universo. Ao estabelecer na sua ficção que caminho e que formato de ideias/práticas podem ser tidas como verdadeiras, ao mesmo tempo em que não se dá conta de sua limitação e posição política assumida, Descartes deu novas e perigosas bases para que o conhecimento seguisse visto como se independesse das relações de poder que lhe são inerentes. Mas, como bem nos recorda Foucault (2000, p. 131), a "Truth is a thing of this world: it is produced only in virtue of multiple forms of constraint" ${ }^{24}$. Toda ideia de verdade carrega consigo poder.

Ao se apresentar descaradamente como uma ficção, a arte fica em posição privilegiada para contestar a pretensão de captura do 'real'. Ao nos depararmos com uma obra de arte somos convocados a nos portar como sujeitos criadores e temos a chance de nos dar conta de que não criamos 'a coisa' só na arte, mas por onde passamos. Nietzsche (2006, p.100), poeticamente filosofando, nos confirma a força e a importância da ficção descarada: “... poets lie too much: he is right - we lie too much. We also know too little and are bad learners, thus we simply have to lie"25. A arte, representada nessa passagem pela poesia, é a mentira desejável. Mentimos porque sabemos pouco, não aprendemos bem, restando-nos criar, inventar, ficcionar. A arte, para Nietzsche, não é do reino da verdade e isso é um grande elogio. A arte não acha que sabe definitivamente e, por isso, pode narrar a vida, ao mesmo tempo em que a constrói, segundo sua narrativa.

Certamente, não se trata de imaginar que a arte esteja imune ao poder. Qualquer ficção que se estabeleça estará numa relação de poder. O caso, porém, é que a arte parece conseguir falar a seu tempo e do seu tempo sem recair na armadilha da universalidade. Em termos mais filosóficos, podemos apontar que não há um significado 
universal na arte. Não obstante, há uma capacidade potencial de convocar os sentidos dos sujeitos de qualquer tempo e de qualquer local. Ou seja, as categorias de particular e universal são, se tomadas rigorosamente, inadequadas para a arte. A arte é particular e universal. Cada obra de arte é, e assim se assume, uma produção particular, expressa por elementos temporais, espaciais e culturais que remetem a um contexto específico. Mas cada uma é, também, uma proposta de, através de suas particularidades, falar sobre aquilo que transcende o particular.

Por essa característica de fluir entre o particular e o que o transcende, a arte tem mais possibilidades de fomentar relações dialógicas ${ }^{26}$ e democráticas, facilitando que os arranjos de poderes sejam, permanentemente, postos em xeque. Assim, o desafio que a arte propõe para as ciências e para as filosofias não é o de tentar desvincular o poder e a verdade. Se fizesse isso, a arte estaria, contraditoriamente, ao lado dos que defendem a neutralidade do saber. A provocação mais difícil é repensar a verdade em termos do poder que ela exerce. Ou seja, ao invés de esvaziar o Outro, como faz a verdade, negando que estamos sempre no terreno das relações de poder, cabe revisitar as teorias que ficcionamos não apenas nos limites dos seus discursos conceituais, mas em seu alargamento sobre a vida cotidiana. Ao reconhecermos explicitamente que somos os criadores de conhecimentos fictícios ficamos mais próximos de lidar com o Outro, percebendo que ele não é um mero objeto que precisa ser controlado. Ademais, pela assunção da ficção somos levados a considerar a necessidade de reinventar constantemente. Se nossos discursos não correspondem ao real, nossa narração do mundo e da vida está permanentemente aberta.

\section{(In)Concluindo...}

Traçada esta trilha, minha deliberadamente provocativa defesa da arte 'contra a verdade' é, principalmente, uma aposta na importância da diferença. Muito temos falado sobre diferença nos últimos anos. Em todas as esferas, inclusive. Na filosofia contemporânea a diferença se torna um tema pulsante. Pensadores e pensadoras emergem e filosofam tendo a singularidade e a complexidade como pontos de referência. Somente após essa virada fomos capazes de validar que a filosofia não nasceu só na Grécia e que nem todos os filósofos são europeus ou com passaportes carimbados lá. 
Ao sublinhar isso quero que se note que, em absoluto, o que coloco aqui é uma novidade. Entendo, no entanto, que há ainda muita estranheza e resistência frente ao que a arte pode nos ensinar/propiciar, não só na filosofia, mas na ciência, na religião, na política, na educação, enfim, em quase todas as instâncias do nosso dia a dia. Ouso conjeturar que, como repetido tantas vezes nas histórias, a onda de reconhecimento da diferença, gerou também seu contrário: vivemos no mundo hoje também um forte movimento anti-diferença. Um movimento que precisa ser entendido em sua complexidade. Ou seja, tanto como um movimento conservador, no sentido que pretende conservar o que está consolidado e que serve de sustento a tantas conquistas, quanto como um movimento típico humano de receio e repúdio diante do imprevisível e do novo.

Se olharmos o que estou chamando de movimento anti-diferença, veremos sua recorrência aos argumentos universalizantes da verdade que, nutridos por séculos e séculos, estão na base da maior parte (senão de todas) das instituições sociais. Segundo esse movimento, a defesa da diferença é a defesa do fim de tudo o que conhecemos: um cataclismo devastador que não deixará pedra sob pedra da vida. A diferença aparece como a comedora de criancinhas, a destruidora dos lares, aquela que nos deixará sem norte, que acabará com nossos empregos, com nossas escolas, com nossas igrejas. Assim, a diferença parece algo completamente novo e estranho a nós. Por isso, arma-se uma batalha contra ela (ou o que se imagina que ela seja). Reforçamos nossos muros. Afiamos nossas facas. Endurecemos as leis. Ficamos vigilantes e pregamos, como poucas vezes, um apego estrito à ordem, à clareza e à distinção.

Faz-se tudo isso, porque se tem tanto medo de considerar a diferença, que não nos permitimos olhá-la e ouvi-la de frente. E, como somos míopes, de longe ela é um bicho papão. Perdemos de vista que a diferença me habita e, em última instância, sou eu (e você também, leitor(a)!). Eis que, a defesa da diferença não ameaça nossa existência, mas a reconfigura. Não acaba com nossas ciências, famílias, escolas, religiões, filosofias, mas as coloca em perspectiva.

$\mathrm{Na}$ arte temos uma oportunidade singular e poderosa de nos relacionar e conhecer as diferenças de uma maneira aberta, receptiva e continuamente em devir. Ao contrariar a lógica da verdade moderna, da neutralidade das quantidades, do controle violento, da subjetividade vazia, a assumida ficção sugerida pela arte nos provoca a pensar outra(s) epistemologia(s). Outra(s) epistemologia(s) que se abre(m) para o processo constante e infindável de nos sabermos/nos intuirmos com um eu que é sempre nós. 
Notas

1. Bignotto (2001, p. 156) mostra que "(...) desde o começo o humanismo renascentista esteve associado a um plano de educação". Daí que os chamados studia humanitatis substituíram o trivium e o quadrivium, visando garantir uma formação adequada do bom cidadão e não só do bom cristão.

2. A expressão "vida ativa" é uma oposição direta à noção medieval de "vida contemplativa" e refere-se aos setores ligados à vida terrena e das cidades, em especial, à dimensão política. "A construção de uma nova maneira de ver a política, a partir do uso intensivo da herança greco-romana, foi talvez o traço mais original do Renascimento e forjou algumas das bases do pensamento político moderno (...)” (BIGNOTTO, 2001, p.86/87)

3. "Verdade' deve ser entendida como um sistema ordenado de procedimentos para produção, regulação, distribuição, circulação e operação de afirmações".

4. Certamente, não são apenas nessas obras que encontramos as considerações cartesianas sobre o problema do conhecimento. Embora não sejam nem os primeiros, nem os últimos escritos do autor, $O$ Discurso e as Meditações se destacam por seu objetivo de lançar as bases de um novo sistema metafísico. Daí O Discurso do Método ter ficado conhecido como a obra inaugural da filosofia moderna.

5. No livro IX (10, 1051 b 5) da Metafísica, Aristóteles afirma: "O ser verdadeiro e falso das coisas consiste na sua união ou na sua separação, de modo que estará na verdade quem considera separada as coisas que, efetivamente, são separadas e unidas as que (sic) coisas que, efetivamente, são unidas; ao contrário, estará no erro quem considera que as coisas são contrárias do que efetivamente são" (p.429).

6. De certa maneira, tanto O Discurso, quanto as Meditações podem ser lidas como um convite de Descartes aos leitores e leitoras de verificarem por eles(as) mesmos(as) o que nas obras ele apresenta: "Assim, meu desígnio não é ensinar aqui o método que cada qual deve seguir para bem conduzir sua razão, mas apenas mostrar de que maneira conduzi a minha. (...) espero que ele será útil a alguns, sem ser nocivo a ninguém...” (1973, p. 38).

7. Aqui me refiro, especificamente, aos livros em foco nesse artigo: $O$ Discurso sobre o Método e Meditações Metafísicas.

8. "De onde nascem meus erros? A saber, só do fato de que, sendo a vontade muito mais ampla e mais extensa do que o entendimento, não a contenho nos mesmos limites, mas a estendo também às coisas que não entendo (...)" (DESCARTES, 2005, p. 90).

9. Importante ressaltar que, sob hipótese nenhuma, suponho aqui que cabe integralmente a Descartes e à sua filosofia a responsabilidade exclusiva da assunção do estatuto da ciência moderna. Longe disso, a metafísica cartesiana bebe e também deságua em um solo fértil no qual estão muitos pensadores que lhe antecedem e lhe sucedem. Exemplo nítido disso é a referência que 
Descartes faz a Galileu n'O Discurso, fazendo-nos entender que sua metafísica é, em parte, uma resposta e uma extensão a/de um projeto maior de guinada nas ciências.

10. Galileu defende a ideia de que o 'livro da natureza' está escrito em caracteres matemáticos. GALILEI, G. O ensaiador. In: Os pensadores (volume XII). São Paulo: Abril Cultural, 1973.

11. Pelas limitações de tamanho próprias ao formato do artigo, irei me restringir aqui às mudanças ocorridas relativamente ao espaço e ao tempo. As transformações nas percepções de trabalho, transporte, moedas, movimento são encontradas indicações em: Ingold (2007); Duarte Jr. (2000); Gorz (2007).

12. "Mas o mundo que é representado no mapa é um mundo sem habitantes: não há ninguém lá, nada se move ou faz qualquer som".

13. Lima Vaz aponta: "O projeto cartesiano cumpre, desta sorte, as exigências fundamentais do paradigma mecanicista e eis por que a filosofia e, de alguma maneira, toda a cultura moderna se reconhecem na sua identidade histórica pelos traços cartesianos da sua origem".

14. "A máquina cartesiana resulta de um desmembramento do corpo natural e de sua ressíntese, manipulação e controle de acordo com os ditames de um modelo racional".

15. "O conceito dominante de individualidade vigente na América do Norte - o dito 'self individualista' - é caracterizado como um self poderoso, delimitado e autônomo com 'demarcações psicológicas específicas, um locus interno de controle e uma vontade de manipular o mundo exterior para suas próprias finalidade'(CUSHMAN, 1990, p. 600)”.

16. “A descrição dos órgãos corporais devotada ao prazer nunca ocorre sem uma apreciação das quantidades numéricas, isso se dá porque o balanço mesmo daquelas medidas é um pressuposto para que se encontre o valor do objeto designado".

17. “...Cushman aponta que essa é a essência da atual noção de individualidade ocidental: a do 'self vazio'. Esse 'self vazio', cortado e removido das tradições comunais que outrora lhe davam orientação para o que constituía uma vida significativa e plena, agora volta-se para obtenção de sentido e completude através de atos de consumo“.

18. Toco nessa temática nos artigos: "Convite à perversão" e. "Subjetividade e educação musical: uma reflexão a partir da filosofia”.

19. Esse espaço não é, necessariamente, um espaço físico. Antes é espaço social, de práticas sociais que se desenham e se redesenham, abrindo e fechando brechas constantemente.

20. "Vida como um fim é qualitativamente diferente da vida como um meio".

21. Certamente, não faltarão aqueles que perguntarão: “Mas, como os assuntos pragmáticos do saber e da vida serão resolvidos se abrirmos mão da clareza e da distinção?”. A estes convém 
sempre lembrar que na lógica aqui professada não há uma exclusão da ciência, da filosofia e nem da clareza, de uma vez por todas. O que há é uma aproximação diversa das ciências e filosofias em relação a estas categorias em suas pressuposições e limites. Obviamente, com isso, surge um novo problema epistemológico a ser enfrentado: por quais critérios as múltiplas narrações sobre um fenômeno podem ser acatadas? Responder a essa questão, porém, excede os objetivos deste artigo.

22. A banda de Möbius é um espaço topológico que resulta da colagem das extremidades de uma fita após dar-se meia volta em uma delas. Apesar de ter sido inicialmente estudada para fins geométricos, a banda instigou outras áreas, como a psicanálise, a computação gráfica e a arte.

23. "Objetividade não se trata de um desengajamento, mas de uma estruturação mútua e usualmente desigual, trata-se de assumir riscos em um mundo onde 'nós' somos permanentemente mortais, quer dizer, sem um controle 'final'. Enfim, não temos ideias claras, nem distintas”.

24."Verdade é uma coisa deste mundo: ela é produzida apenas em virtude de múltiplas formas de restrições".

25. “... poetas mentem muito: ele está certo - nós mentimos muito. Nós também sabemos muito pouco e somos maus alunos, por isso nós simplesmente temos que mentir”.

26. Não suponho que relações dialógicas sejam relações harmoniosas, excluindo os conflitos. Longe disso, entendo que apenas numa situação de diálogo as diferenças possam apresentar-se como tais sem serem rechaçadas a priori.

\section{Referências}

ARISTÓTELES. Metafísica. São Paulo: Loyola, 2002.

BARBOSA, A.M. Arte-educação no Brasil. $7^{\text {a }}$ ed. São Paulo: Perspectiva, 2012.

BIGNOTTO, N. Origens do republicanismo moderno. Belo Horizonte: UFMG, 2001.

BITENCOURT, J. A. Descartes e a invenção do sujeito. São Paulo: Paulus, 2017.

DOMINGUES, I. O grau zero do conhecimento: o problema da fundamentação das ciências humanas. São Paulo: Loyola, 1991. 
DESCARTES, R. O discurso do método. In: Os pensadores (volume XV). São Paulo: Abril Cultural, 1973.

Meditações metafísicas. 2a. ed. São Paulo: Martins Fontes, 2005.

DUARTE JR., J.F. O sentido dos sentidos. 2000. Tese (Doutorado em Educação), Faculdade de Educação, Universidade Estadual de Campinas.

. Fundamentos estéticos da educação. $4^{\mathrm{a}}$ ed. Campinas: Papirus, 1995.

FOUCAULT, M. Truth and power. In: Essential works of Foucault 1954-1984 (volume three). New York: The new press, 2000.

GALILEI, G. O ensaiador. In: Os pensadores (volume XII). São Paulo: Abril Cultural, 1973 .

GOMES, R.H.S.F. Convite à perversão. Opus: Revista da ANPPOM, v. 21, n.1, 2015, p. 101-118

GOMES, R.H.S.F. Subjetividade e educação musical: uma reflexão a partir da filosofia. Anais do SEFIM, vol. 3, n. 5, 2017, p. 43-55.

GORZ, A. Metamorfoses do trabalho: crítica da razão econômica. $2^{\text {a }}$ ed. São Paulo: Annablume, 2007.

HARAWAY, D. Situated knowledges: the science question in feminism and the privilege of partial perspective. In: FEENBERG, A. \& HANNAY, A. (Ed.). The politics of knowledge. Blooming e Indiana: Indiana University Press, 1995.

HÉNAFF, M. Sade, the Mechanization of the Libertine Body, and the Crisis of Reason. In: FEENBERG, A. \& HANNAY, A. (Ed.). The politics of knowledge. Blooming e Indiana: Indiana University Press, 1995. 
INGOLD, T. Lines: a brief history. Londres: Routlegde, 2007.

JUDOVITZ, D. The culture of the body: genealogies of Modernity. $4^{\mathrm{a}}$ ed. Estados Unidos (sem cidade definida): The University of Michigan Press, 2004.

LIMA VAZ, H.C. Escritos de filosofia $I V$ : introdução à ética filosófica 1. São Paulo: Loyola, 1999.

MARCUSE, H. One-dimensional man: studies in the ideology of advanced industrial society. 5a.ed. Boston: Beacon press, 1968.

MORIN, E. Ciência com consciência. 8ª ed. Rio de Janeiro: Bertrand Brasil, 2005.

NIETZSCHE, F. Thus spoke Zarathustra. Cambridge: Cambridge University Press, 2006.

PERLER, D. René Descartes: O projeto de uma refundamentação radical do saber. In: Kreimendahl, L. (org.). Fỉósofos do século XVII. São Leopoldo: Editora Unissinos, 2007.

VANDENBORN, E. The social implications of the individualistic selffor the Child Protection System in British Columbia. 2014. Dissertação (Mestrado em Psicologia da Educação), Faculty of Education, Simon Fraser University.

Recebido em: 05/08/2019

Aceito em: 19/11/2019

Publicado em: 22/04/2020 